\title{
Scenario Development and Delphi Application in Life Cycle Assessment for Assessing Environmental Impact of New Technology Case Study: Removal of Wind Turbines Project
}

\author{
Devina Fitrika Dewi \\ Technische University of Harburg, Hamburg, Germany \\ email: devina.fitrika@gmail.com
}

\begin{abstract}
Certain technology is intended to create eco-efficient products or process or is developed as answer to the recent challenge. This kind of technology consequently can also create another impact therefore it shall be assessed and analyzed.

The focus of the study is on assessment method namely Life Cycle Analysis (LCA), Scenario development and Delphi application. The objective is to understand benefits and drawbacks of the combined methodology and observe practicality of its implementation for assessing new technology. The distinctive feature comes from the combination of social and technological foresight (as Delphi application) and future studies (as Scenario development) which are applied in the environmental assessment of a product (by Life Cycle Analysis).

The utilization of LCA-Scenario-Delphi case study as an explanatory example is presented in the Removal Wind Turbines Project by the Danish Energy Agency. The wind turbine is considered new technology with some of it phases are yet to occur, for example: removal of turbines after phase out stage. Technology Assessment by LCA-Scenario-Delphi is complicated procedure, but necessary to validate the results. The drawbacks of this procedure are extensive time it consumes and the dependency on public participation and/or expert willingness to participate. Nonetheless, its advantages are due to its interactive feature; integration of knowledge from different areas of expertise and its assessment's characteristic which focuses on process.
\end{abstract}

Keywords: Scenario, Delphi, Life cycle assessment, removal of wind turbines

\section{Background}

Since technology often has unintended consequences which are either undesirable or, in worst case, can be damaging, an assessment that analyze impacts of the technology is needed. Technology assessment has several methods and one among them is the combination of Scenario development and Delphi application in Life Cycle Assessment (LCA) of new technology or product. Technology Assessment generally cannot be achieved with a single scientific approach as well as with a sole method (VDI, 1993), in particular for the technology that is still very new (in developing phase/under development), or product that is not yet have a full life cycle. The procedure to perform the combined three methods in assessment of new technology is investigated in this paper. The procedure is given by SETAC Framework. It is also necessary to analyze the advantages and disadvantages of the combined LCA-Scenario-Delphi method based on a case study. The case study of wind turbines removal is important as explanatory example.

The main objective of this paper is to analyze the methods of Technology Assessment, namely LCA, Scenario development and Delphi application. The steps needed in undertaking Technology 
Assessment with the combined LCA-Scenario-Delphi methodology were investigated. Finally, discuss the benefits and the drawbacks of the combined methodology and observe implementation on a case study. The results will lead to better understanding of the procedure and benefits in the implementation of technology assessment, in particular by the means of the combined methodology and specifically for the certain characteristic of technology/product.

\section{Methodology}

How to perform Life Cycle Assessment (LCA) combined with Scenario Development and Delphi Application as technology assessment? What are the advantages and disadvantages of this particular method? To answer this question, several sub questions are formulated:

- What is study on technology assessment using the LCA application with the Delphi and Scenario Development? How to conduct it? Why the three methods should be used in combination? What are conclusions regarding the method?

- What is the characteristic of technology which should be assessed using LCA-Scenario- Delphi?

- What is the applicability of the former study of Technology Assessment using the LCAScenario- Delphi? Is there any other study using the combination of two or three choices of the aforementioned methods?

Since the research question refers to an exploratory study, the research method was determined to be a case study. Since the wind turbine is considered new technology with some of its phase is yet to occur, therefore the removal of the turbines after its phase out stage is decided as case study.

\section{Technology Assessment Methods}

Life Cycle Analysis (LCA) is the most common approach in assessing the potential environmental impacts and defined as "an objective process to evaluate the environmental burdens associated with a product, process, or activity by identifying energy and materials used and wastes released to the environment, and to evaluate and implement opportunities to affect environmental improvements" (SETAC, 1976). LCA methodology is subsequently developed to the recent ISO 14040 and 14044 (2006). This LCA procedure ISO 2006 (see Figure 1) is considered as one of the most advanced standardized procedures to evaluate environmental impacts related with products and/or technology. Scenario Development as Technology Assessment method is described in Malsch et al (2008) as a qualitative literary method for holistically describing complex potential of the future situation. The 
objective of the scenario development is to identify existing trends and key uncertainties and combine them in pictures of the future, not covering all eventualities but discovering the boundaries of future outcomes (Schwarz, 2008). The scenario studies are illustrated by the main questions about the future as: What will happen?; and then be addressed by Predictive scenarios which is consisted of two different types. The first type is a forecast scenario that addresses what-willhappen question based on the conditions that likely unfolds in the future. The second type is a what-if scenario that corresponds to what-will-happen question on the condition of some specified events (Borjeson, 2006).

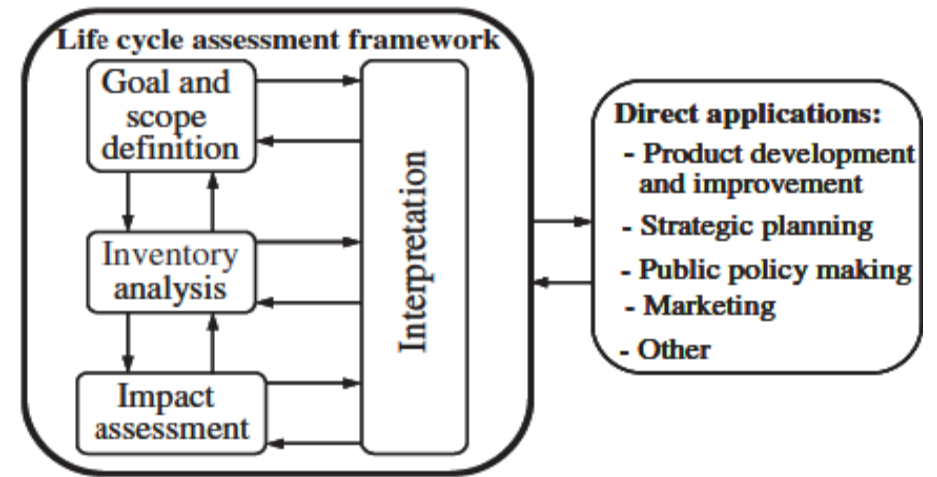

Figure 1. Stages in LCA (ISO 14040, 2006)

Delphi application, or known as Delphi expert opinion survey, is a method for finding ideas and making prognoses that systematically ascertains the insight and forecast of selected experts and returns a measure of central tendency (VDI, 1993). Delphi application was developed by Olaf Helmer and Norman Dalkey in 1953 at the RAND Corporation with the aim of improving the use of expert opinion in policy-making. The core of the Delphi application is that a pool of experts deals with a certain problem that lies in the future by a consensus (Schwarz, 2008).

\section{Wind Turbines Case Study}

LCA-Scenario-Delphi methodology is implemented in a real case study in assessing wind turbines.

\section{Background of The Case Study}

The wind power technology is generally recognized as one of the most environmentally sound technologies for producing electricity, since it is necessary to acknowledge that even the renewable energy technologies are also subject to assessments of their impact on the environment (Bjerrregaard, E. and Dannemand Andersen, P., 2001). Many LCA studies are performed on wind power technology and some of the latest are by Martinez et al (2008) and Weinzettel et al (2008). 
Hence, as LCA investigates the environmental impacts throughout the full life-cycle of a product or system, and also since the assessment methodologies for environmental impacts usually are based on historical data or state of the art of technology therefore as the SETAC framework discussed earlier, the challenge is occurred for new technology or technologies that are expected to change over long period of planning (Bjerrregaard, E. and Dannemand Andersen, P., 2001).

Both papers by Bjerrregaard, E. and Dannemand Andersen, P. (2001) and Borup, M. and Dannemand Andersen, P (2001) used LCA since LCA can locate source of, for example, environmental pollution or resource use of upstream and downstream processes and eventually improve the efficacy of environmental aspects of the technology (WEC, 2004). Wind turbines phases are showed in Figure 2 with an emphasis on the decommissioning part.

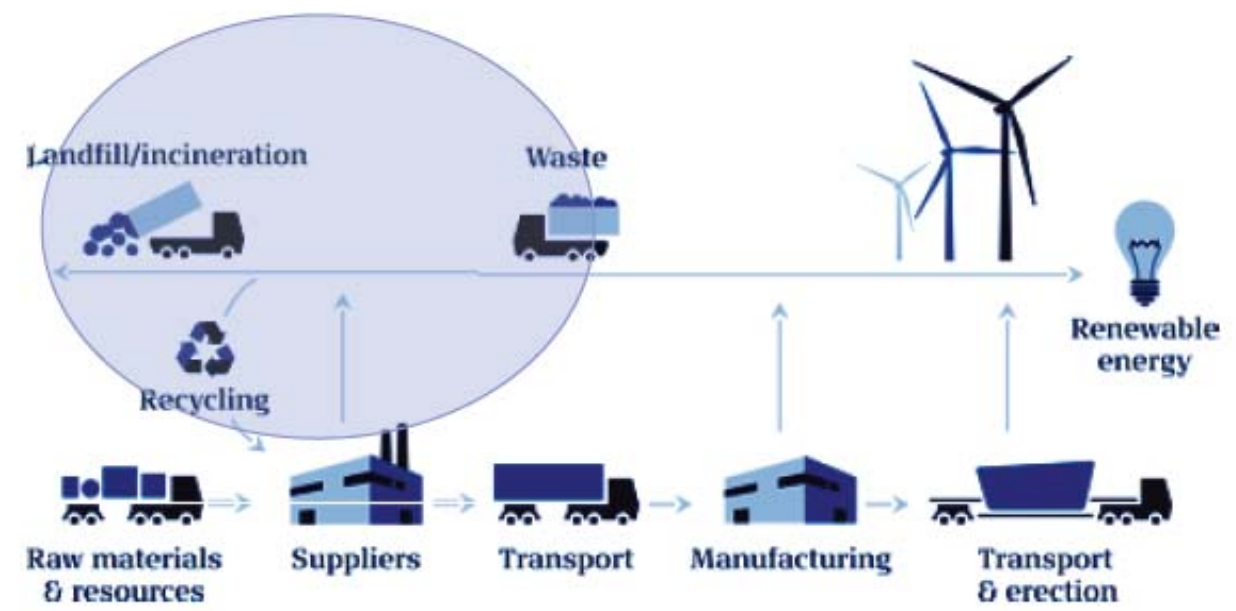

Figure 2. Life Cycle phase of Wind Turbines Technology

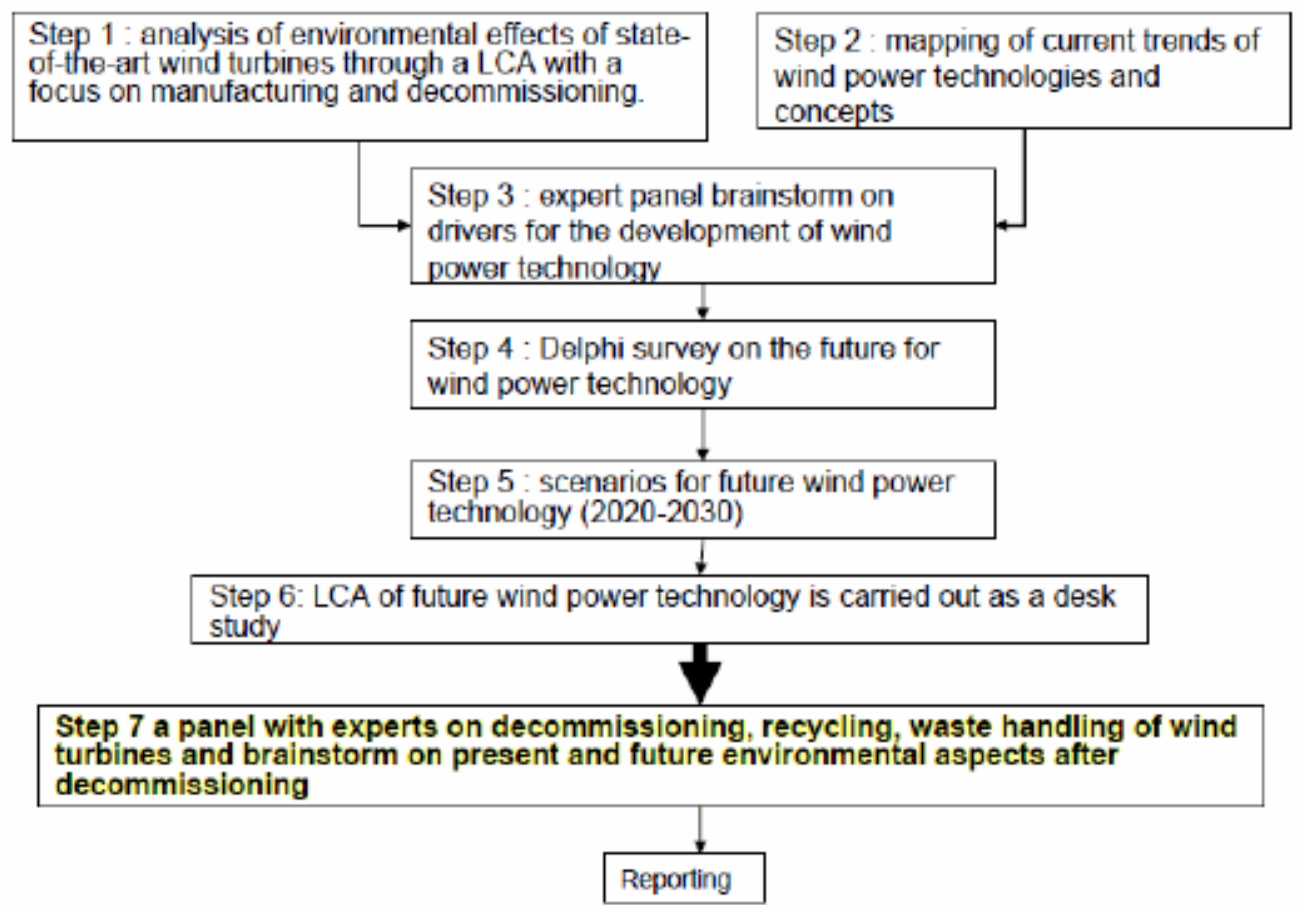

Figure 3. Project Phases of LCA-Scenario-Delphi (Borup, M., and Dannemand Andersen, P., 2001) 


\section{Project Phases for The Study}

Phases to perform the combined LCA-Scenario-Delphi methodology are explained in Figure 3.

LCA the scenario development and Delphi application is also employed with the following reasons (Borup, M., and Dannemand Andersen, P., 2001):

a. A blind spot on environmental impacts analysis on certain phase of technology's life cycle

b. Limited historical data and technology's characteristic as basis for assessing environmental effects

c. The development phase of design, regulatory demands, and organizational responsibilities which will determine the future phase implementation and its impact.

Step 1: Analysis of environmental effects of state-of-the-art wind turbines through LCA with a focus on manufacturing and decommissioning to find the most important negative effects on the environment. The results were:

a. Voluminous waste from tower and foundation (e.g. from steel production)

b. Hazardous waste from components in nacelle (e.g. from steel alloys)

c. Greenhouse effects (e.g. from steel production and surface treatment)

Step 2: Mapping of current trends of wind power technologies, which was also performed based on previous studies, to find trends which influence the future design of wind turbines.

Step 3: The first Delphi application expert which consist of panel brainstorm on the drivers for the development of wind power technology. This step was carried out as a workshop with the objectives are to agree on the most important factors determining future wind power technology, in particular for some cases that cannot be extrapolated from previous studies (Step 2) and which have high potential impact and high uncertainty.

Step 4: The second Delphi survey on the future for wind power technology. The process contains a questionnaire with 24 statements based on the results from the Step 3, which was distributed to the attendants of the European Wind Energy Conference in Copenhagen, July 2-7, 2001.

Step 5: Scenarios development for future wind power technology. In this step the scenario based on previous steps was drawn. These scenarios are technical scenarios, described possible designs of wind turbines with lists of materials and will define process for recycling phase:

a. Scenario of the actual, as described in Table 1.

b. Scenario of $100 \%$ recycling of metals

c. Scenario of $95 \%$ recycling of metals 


\begin{tabular}{|l|l|}
\hline Materials & Scenario \\
\hline Steel blades & $90 \%$ reuse \\
\hline Stainless steel & $90 \%$ reuse \\
\hline Cast iron & $90 \%$ reuse \\
\hline Cobber & $95 \%$ reuse \\
\hline Aluminium & $90 \%$ reuse \\
\hline Plastic, PVC & $100 \%$ deposit \\
\hline Glass fibre & $100 \%$ deposit \\
\hline Oil & $100 \%$ incineration \\
\hline Lead & $90 \%$ reuse \\
\hline Zinc & $90 \%$ reuse \\
\hline
\end{tabular}

Table 1. The actual scenario of decommissioning of wind turbines, inspired by Elsam (2004)

This scenario can be considered as a What-if scenario, referring to SETAC Framework, since it has the characteristics of answering question: what will happen, on the condition of some specified events, and has quantity comparison with other alternatives. As the framework, time horizon is determined by lead time for developing new products and in this case is about 2040- 2050 for removal phase.

Step 6: An LCA of the future wind power technology. Based on the previous scenario, LCA can reveal potential environmental advantages and adverse effects of the designs as is showed in Fig.4 below:

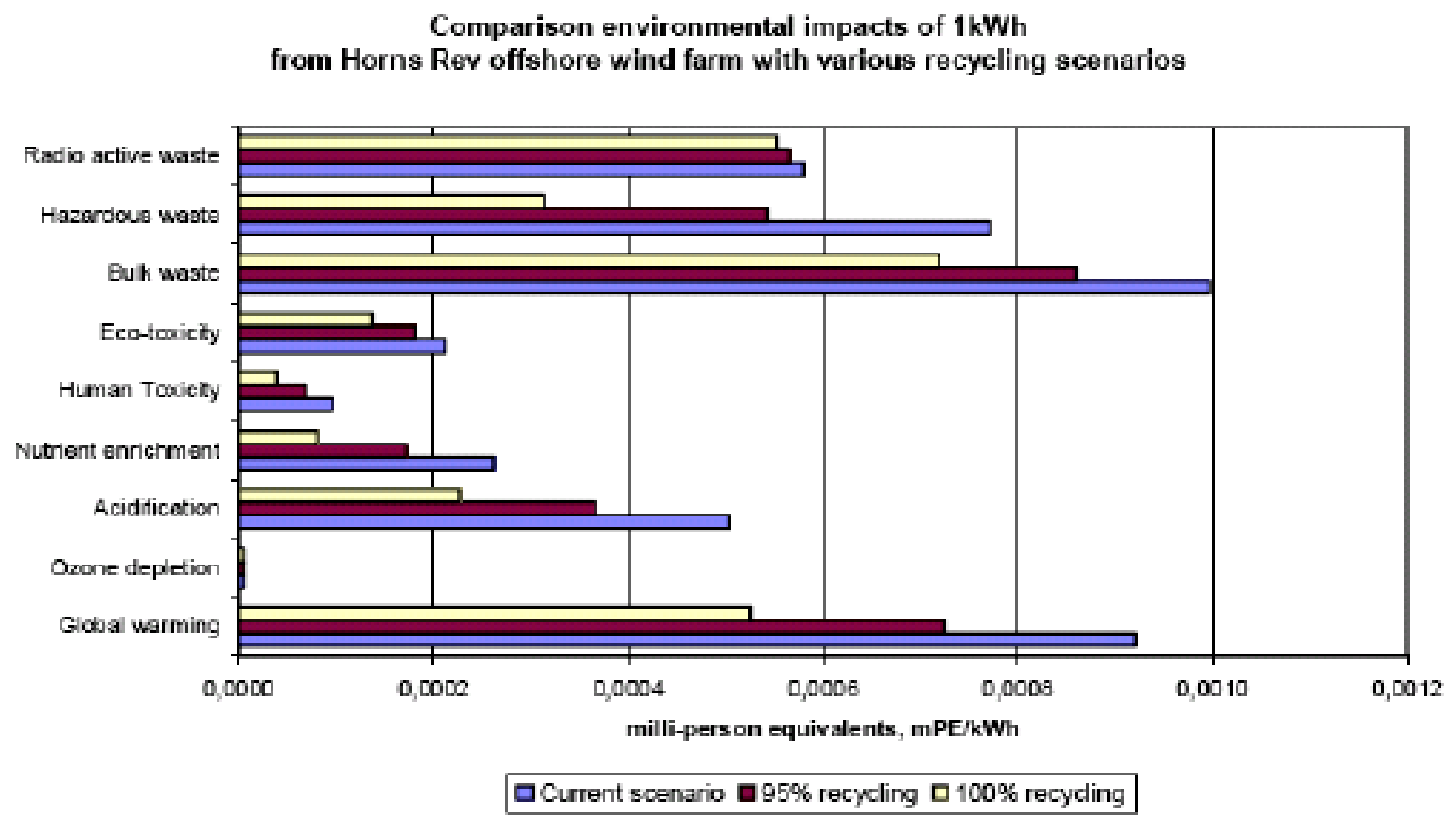

Figure 4. Comparison of environmental impact (Elsam, 2004)

Step 7: The step 7 is second Delphi application which contains a panel of experts on decommissioning, recycling, waste handling of wind turbines and brainstorm on present and future environmental aspects after decommissioning. 


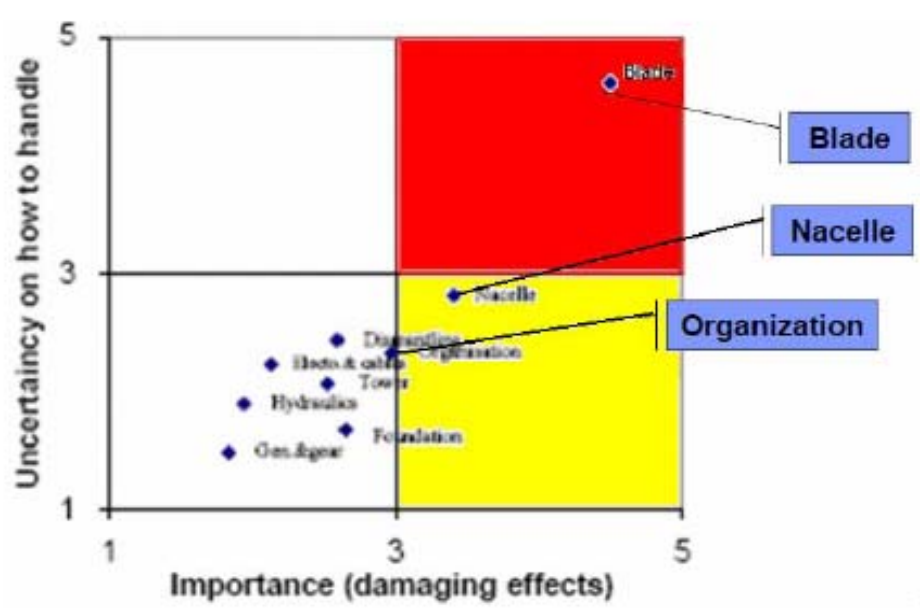

Figure 5. The Result of Panel Expert on Decommissioning effect on Environment (Borup, M., and Dannemand Andersen, P., 2001).

The expert panel is came from representatives of recovery companies, wind turbine producer, consultants and knowledge institutions on waste handling and wind power plants researchers.

The step 7 is considered as the most important step with the result as describe in Figure 5 as a graphic with the parameter of importance in environmental impact (damaging effects) and parameter of uncertainty (how to handle). The blades are major problem in the removal phase of wind turbines and there is much uncertainty concerning how to get rid of them in a proper and safer way due to its material, the same problem as the nacelle. The institutional and organizational structure of wind turbines removal is possible to be identified: existing or specialized recovery companies do the work or strategic collaboration between wind turbine producers and removal companies.

\section{Discussion}

From the Removal Wind Turbines Study, it is concluded that the utilization of selected scenario of recycling of materials has been proved to be important to the total environmental impacts. Without the application of scenario development, the environmental impacts would be up to 6 times as high. However, the procedure on the Scenario development by using Delphi application (first and second Delphi or step 3 and step 4) to extract data and formulate the valid scenario and eventually applying them in LCA studies is a very difficult and time consuming task. It is also underlined that judgmental methodologies depend entirely on external expert’s willingness to participate.

Hence, despite all the challenges, the combined LCA-Scenario-Delphi methodology offers a solution to complex problem or new technology. The methodology combines perspective of life cycles, strategic and dynamic of foresight process and systematic integration of these aspects. 
Essential aspect of the methodology is interactive feature, process-oriented character and integration of knowledge from different areas of expertise. Other technology that can be assessed using this method will also be discussed.

The procedure based on 'Removal wind turbines' is considered probable to be simplified, for example by combining step 1 and 2 for trend analysis, and step 3 and 4 for Delphi survey, followed still by unchanged procedure of scenario development and then LCA. The basic procedure from case study and SETAC framework should sufficient as guideline to replicate the similar combined methodology for other technology assessment.

The quality of combine LCA-Scenario-Delphi, should also be observed from how the result was used by the related parties. The Removal Wind Turbines Study is employed in environmental product declaration and LCA studies by Vestas Wind Energy A/S. as Life cycle assessment of wind power plants based on Vestas V90-3.0 MW turbines and on Vestas V82-1.65 MW turbines

From the search with keywords of: LCA, scenario development and Delphi application with range of time between 2007 to present (June 2008); rarely found any article which explained about utilization of LCA-Scenario-Delphi combined in one technology assessment. Although Technology Assessment method mainly implemented in combination in order to deal with particular technology or problem. Combined method as Scenario-LCA and Delphi-Scenario are not unusual in technology assessment research, although case study found is only for 'Removal Wind Turbines' project. Since disadvantage of this LCA-Scenario-Delphi method is situated in its complicated procedure and time consuming task.

On the other hand, the utilization of the combined three methods is not without drawbacks as it will generate complex route or complicated procedure. The complication of the procedure is also observed as it distinctively can be performed only in particular states. The success of performance LCA-Scenario-Delphi in the previous study by Danish Energy Agency, also relied on expert experiences and willingness in Delphi and public participation, which is the strength of Danish public maturity, or countries/community with developed system. This is probably the reason of no other research using similar methods.

\section{Conclusion}

The utilization of the combined LCA-Scenario-Delphi methodology as Technology Assessment method was described in SETAC guideline and its application was shown in Removal Wind Turbines Project by Danish Energy Agency. The procedure of the combined methodology in the project can be replicated to other technology and can also be modified according to the situation 
with the SETAC Framework as a guideline. The advantage of LCA-Scenario-Delphi methodology is established in its interactive feature, process-oriented character and integration of knowledge from different areas of expertise. The disadvantage is due to its complicated procedure and time consuming task, as well as the need for public willingness to participate. The complicated procedure was required to get the validation therefore the complication of the methodology cannot be avoided, and subsequently becomes time consuming.

\section{References}

Bjerrregaard, E., and Dannemand Andersen, P. (2001). Prospective Life-Cycle Assessment on Wind Power Technology by 2020, TA Datebank Nachrichten Nr. 4 10, December 2001.

Borjeson, L., Hojer, M., Dreborg, K., Ekvall, T., and Finnveden G. (2006). Scenario types and techniques: Towards a user's guide, Futures 38; 723-739.

Borup, M., and Dannemand Andersen, P. (2001). Recycling and removal of offshore wind turbinesAn interactive method for reduction of negative environmental effect.

Elsam Engineering A/S. (2004). Life Cycle Assessment of Offshore and Onshore Sited Windfarm, Ref.HHA/AAH/AWK, Doc No. 200128. Project. 1012063, Vestas Wind System A/S, 20 October 2004.

International Organization and Standization (ISO). (1996). 14040, 14041, 14042, and 14043.

International Organization and Standization (ISO). (2006). 14040, 14041.

Malsch, T., Florian, M., and Fleco, J. (2008). Methods of Technology Assessment: Reader Summer 2008, Hamburg University of Technology, Institute of Technology and Society.

Martınez, E., Sanz, F., Pellegrini, S., Jimenez E., and Blanco, J. (2008). Life cycle assessment of a multimegawatt wind turbine, Renewable Energy, 1-7.

Pesonen, H., Ekvall, T., Fleischer, G., Huppes, G., Jahn, C., Klos, Zbigniew S., Rebitzer, G., Sonnemann, Guido W., Tintinelli, A., Weidema, Bo P., and Wenzel, H. (2000). Framework for Scenario Development in LCA; International Journal of Life Cycle Assessment, 5 (1) 21-30.

Schwarz, J. (1976). Assessing the future of futures studies in management, Futures 40 (2008) 237246 SETAC Society for Environmental Toxicology and Chemisty. A technical framework for life cycle assessment. Washington, DC.

SETAC. (2008). Society of Environmental, Toxicology and Chemistry; www.SETAC.org, assessed 29 August 2008.

Spielmann, M., Scholz, R.W., Tietje, O. S., and De Haan, P. (2005). Scenario modelling in prospective LCA of transport systems: Application of formative scenario analysis; International Journal of Life Cycle Assessment, Volume 10, Issue 5, September 2005. 
Spielmann, M., de Haan, P., and Scholz, R.W. (2008). Environmental rebound effects of high-speed transport technologies: a case study of climate change rebound effects of a future underground maglev train system, Journal of Cleaner Production, 16 (2008) 1388-1398.

VDI Guideline 3780. (1993). Technikbewertung Begriffe und Grundlagen: Technology Assessment Concepts and Foundations, VDI Report Nr. 15.

WEC World Energy Council. (2004). Comparison of energy systems using life-cycle assessment; A special report of the World Energy Council.

Weinzettel, J., Reenaas, M., Solli, C., and Hertwich E. (2008). Life cycle assessment of a floating offshore wind turbine, Renewable Energy, 1-6. 